\title{
Raspberry Pi House Safeguard System with Alarm and Email Alert
}

\author{
${ }^{1}$ Vishal Tammana, ${ }^{2}$ Y Pradeep Kumar Reddy, ${ }^{3}$ Sura Sairam, Shaik ${ }^{4}$ Mohammad Zaid \\ Ahammad \& ${ }^{5}$ Parthiban S \\ 1,2,3,4 B-Tech, Dept of CSE Jain University - Faculty of Engineering and Technology \\ Jakkasandra Post,Kanakapura Taluk, Bangalore. \\ ${ }^{5}$ Assistant professor, Dept of CSE Jain University - Faculty of Engineering and Technology \\ Jakkasandra Post,Kanakapura Taluk, Bangalore.
}

\begin{abstract}
This paper is helpful in providing not only safeguard to the house but also alerts the owner through email. This system quickly alerts the presence of an unknown person using Raspberry Pi. This system deploys a Pi camera which takes the picture of the unknown person and includes the image in the email. This system has various areas such as our House s, offices or anywhere, wherever safeguard is necessary, picture captured by using the webcam will send to user email by using SMTP protocol, Email notifications can be sent out to your customers using either Gmail SMTP server or your own SMTP server.
\end{abstract}

Keywords: - web Camera, SMTP, Pip, Electric Circuit.

\section{I.INTRODUCTION}

The main objective of design is to provide effective safeguard for the house. This system helps in continuously monitoring the system wherever and whenever needed. This design provides a wireless and cost-effective solution against unknown person in the absence of owner and control all House appliances from anywhere. The design uses latest wireless communication like Bluetooth, Infrared and Wi-Fi access to the design for safeguard and appliance control. Due to increase in crimes, house safeguarding has become a major issue. Everybody is more concerned about taking up proper measures to prevent intrusion. Working of this system is so very simple and effective.
The PIR sensor detects the human presence other than owner and the Raspberry Pi camera captures the images and sends them to the owner. The PIR sensor detects the unknown person when they come in range of it. The $\mathrm{Pi}$ camera will be triggered captures the images and then saves it. A default mail is created using $\mathrm{Pi}$ and this picture is added to the mail and is sent to the owner. The images that are being captured by the Pi camera are saved with the name, time and also date. The detection range of this design can be adjusted using the PIR potentiometer.

\section{Existing System}

The existing safeguard systems which include Close Circuit Television (CCTV), Finger print 
detector founds to be less reliable, expensive with more power consumption. The drawbacks of getting SIM card Corrupted, network issue using GSM Module and raspberry pi can be overcome by proposed system.

\section{Proposed system}

The propose Raspberry PI House safeguard system is helpful prevent theft in highly secure areas like House, Automated Teller Machine and authorized investment centers with less power consumption, and flexible safeguard device for unknown person detection and door safeguard. This proposed system manages the safeguard concerned issues in a low cost by using PIR and Magnetic sensor. This sensor recognizes the person and capturing the process using Pi camera and sending text messages, emails alert within a fraction of seconds. The system is validated with python 3 coding programming.

\section{4.. METHODOLOGY}

The solution of the problem is dividing the work into 2 modules. Modules -:

\section{Near field communication (NFC) based safeguard}

In this module the detection range of PIR sensor will be tested as well as the Raspberry PI Camera and we will use Python language to save the images.

\section{Way to Email notification}

We will send the email notification and the mail alert. Develop software for mobile device which integrates all 1. Capturing of images 2. Sound Recording 3. Wireless Communications devices 4. Email 5. Email and to identify such electronic devices which uses for House safety to communicate with our programs.

\subsection{BLOCK DIAGRAM}
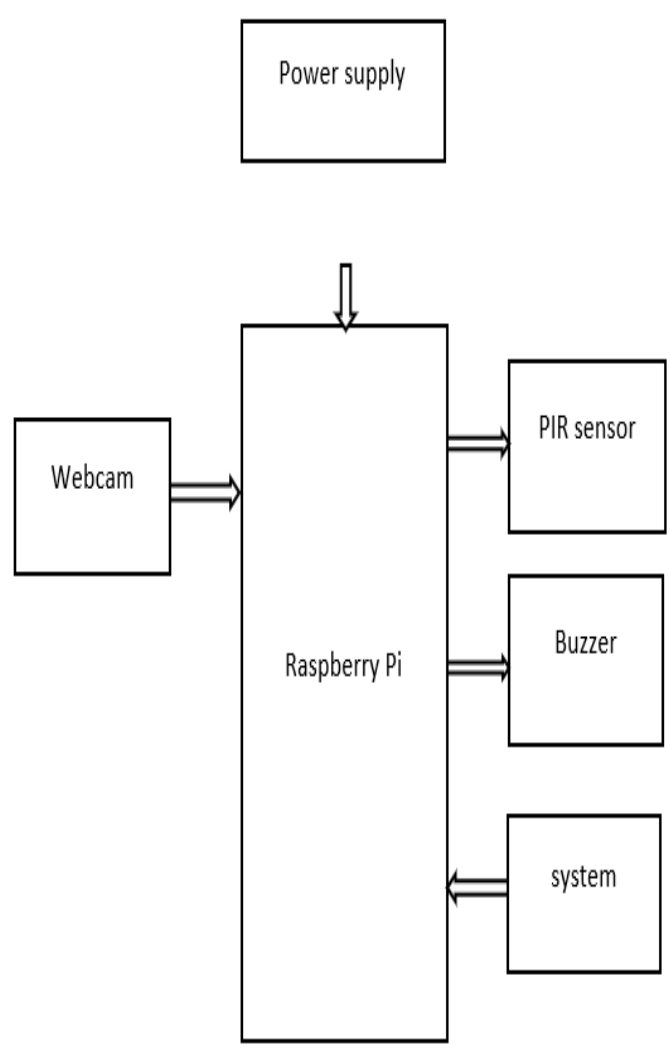

Fig:1 Block diagram

\section{Hardware Requirement}

- Raspberry pi

- USB camera

- PIR sensor

- Buzzer

\section{Software Requirement}

- Python

\subsection{Working}

- The 'PIR' sensor detects an unknown person, activates the camera, capture the picture of unknown person.

- The capture picture sends to owner through e-mail.

- The Buzzer goes on.

\section{HARDWARE COMPONENTS}

\subsection{Raspberry Pi}


A Raspberry Pi series of small single-board computers developed in the United Kingdom by Raspberry Pi Foundation in association with Broadcom. A raspberry pi is a fully functional tiny computer in available in low-cost. It is also known as single board computer, but it is nothing less than a computer. It is basically used for teaching basic computer science in school level. The Raspberry Pi has it's uses in many areas like weather forecasting, Robotics and in several automations. It is available at a very low cost and it's adaptive nature is very helpful in designing many circuits

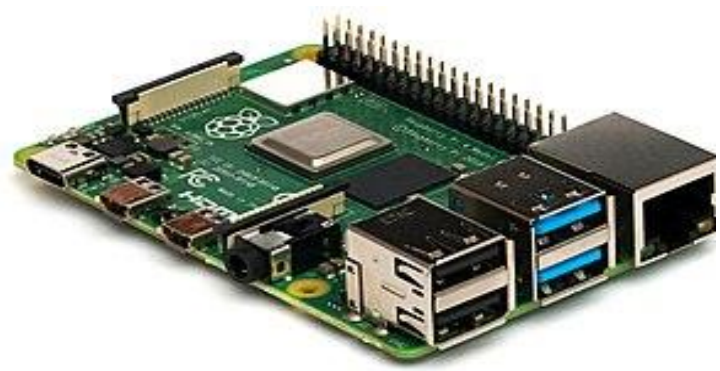

Fig: 2 raspberry pi

\subsection{PIR sensor}

It detects the human presence other than owner and the Raspberry Pi camera captures the images and sends them to the user. This PIR sensor detects the unknown person when they come in range of it. The Pi camera will be triggered and this camera captures the images and then saves it.

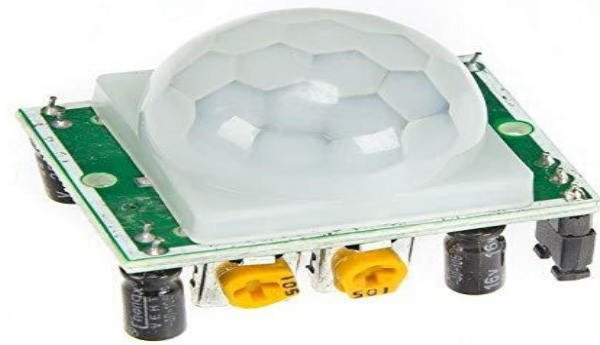

Fig: 3 PIR sensor

\subsection{Buzzer}

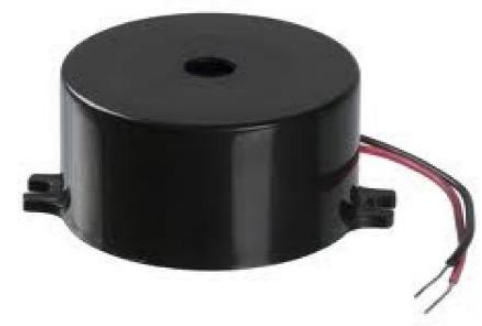

Fig: 4 Buzzer

The buzzer goes high when the PIR sensor detects an intruder.

\subsection{USB camera}

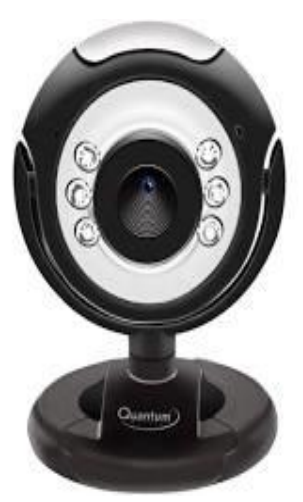

Fig: 5 USB camera

The PIR sensor detects the unknown person when they come in its range. The Pi camera will be triggered and this camera captures the images and then saves it.

\section{Implemetion}




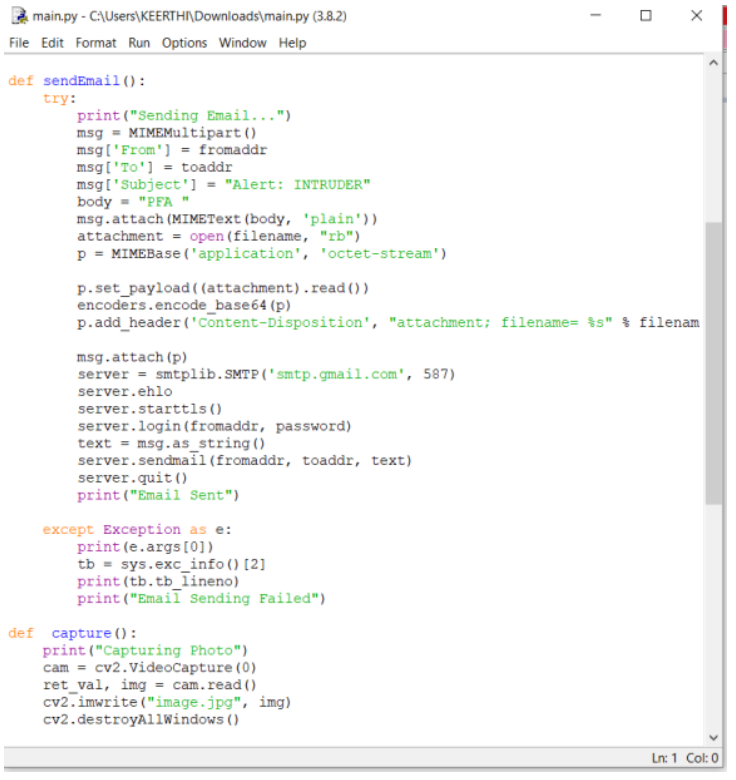

\section{7.design}

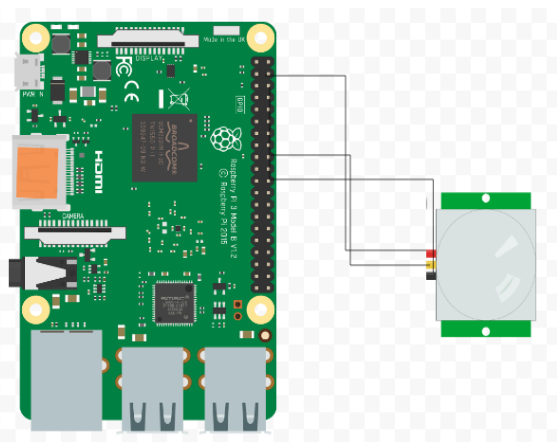

Fig:6 Raspberry pi with PIR sensor.

PIR sensor connection with Raspberry $\mathrm{Pi}$ is show in above Schematic diagram.

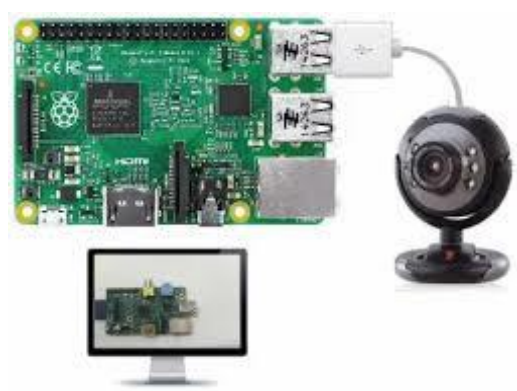

Fig:6 Raspberry pi with USB camera.

USB camera connection with Raspberry Pi is show in above Schematic diagram.

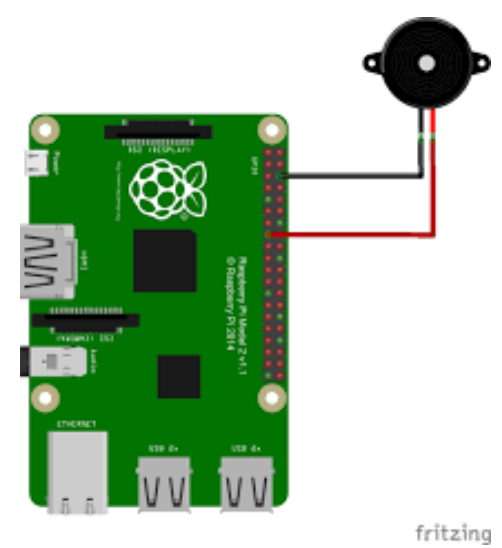

Fig:6 Raspberry pi with Buzzer.

Buzzer connection with Raspberry $\mathrm{Pi}$ is show in above Schematic diagram.

\section{RESULT}

This system works on different wireless communications and latest mobiles for safeguard purpose. The system characteristics involve remote controlling of appliances, detection of intrusion, system safeguard and auto-configuration such that system automatically adjusts the system settings on running hardware support check. Following results will be obtained by this project.

- Firstly, the person is identicalities, which is stored into database by capturing image and sound

- The user will be asked for authentication and authorization through e-mail.

- Safety will be secured by taking immediate actions \& Children will remain safe

- Parents will be informed if they are out of town.

- Monitoring of the house is done remotely.

- A SMS or email alert will be generated if unknown person tries to access entering the house. 
- Recorded images can be sent directly to the user.

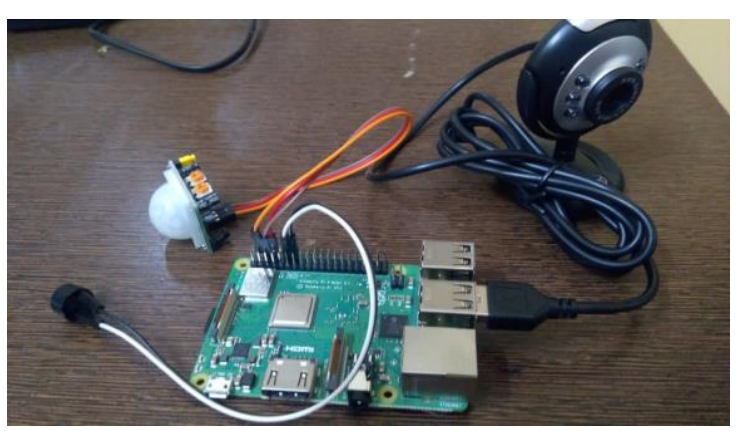

Fig: 7 Prototype Setup

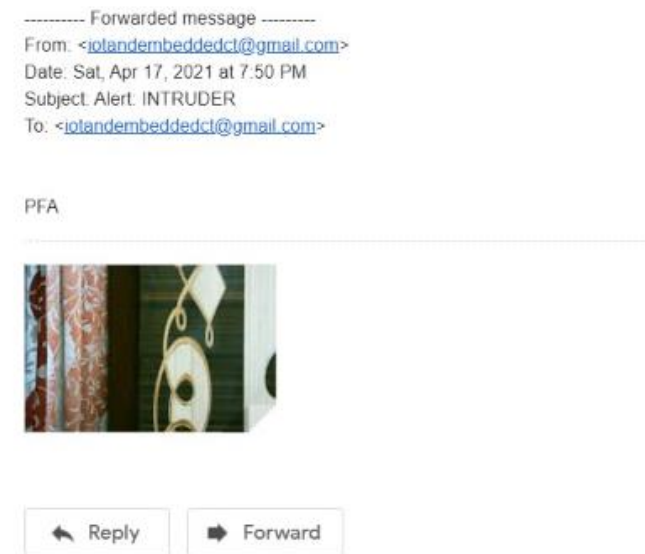

Fig: 8 Result to email

\section{V.CONCLUSION}

Raspberry Pi based House safeguard system has been designed and developed using a Raspberry Pi, PI camera, PIR sensor. The user can get alert anywhere and anytime through email. Whenever any unknown or suspicious movement is detected, it gives loud alarm. Hence the designed system successfully prevents the access of unknown person entering the House.

\section{REFERENCES}

1. Alkar, A. Z., \& Buhur, U. (2005). An Internet Based Wireless Home Automation System for Multifunctional Devices. IEEE Consumer Electronics, 51(4), 1169-1174.

2. Ciubotaru-Petrescu, B., Chiciudean, D., Cioarga, R., \& Stanescu, D. (2006). Wireless
Solutions for Telemetry in Civil Equipment and Infrastructure Monitoring. 3rd RomanianHungarian Joint Symposium Applied Computational Intelligence (SACI) May 25-26, 2006.

3. Conte, G., \& Scaradozzi, D. (2003). Viewing home automation systems as multiple agents systems. RoboCUP2003, Padova, Italy

4. Jawarkar, N. P., Ahmed, V., Ladhake, S. A. \& Thakare, R. D. (2008). Micro-controller based Remote Monitoring using Mobile through Spoken Commands. Journal of Networks, 3(2), 58-63.

5. Murthy, M. V. R. (2008). Mobile based primary health care system for rural India. W3C workshop on Role of Mobile Technologies in Fostering Social Development, Jun 2008

6. Potamitis, I., Georgila, K., Fakotakis, N., \& Kokkinakis, G. (2003). An integrated system for smart-home control of appliances based on remote speech interaction. EUROSPEECH 2003, 8th European Conference on Speech Communication and Technology, pp. 21972200, Geneva, Switzerland, Sept. 1-4,2003.

7. Preeti Sajja "Personalized content representation through hybridization of mobile agent and interface agent", in Susmit Bagchi (Ed.), Ubiquitous Multimedia and Mobile Agents: Models and Implementations, IGI Global Book Publishing, Hershey, PA, USA (In Press) 